\title{
Suspended Trapping Gas Chromatography / Fourier Transform Mass Spectrometry for Analysis of Complex Organic Mixtures
}

\author{
Jeremiah D. Hogan and David A. Laude, Jr. \\ Department of Chemistry, The University of Texas at Austin, Austin, Texas, USA
}

\begin{abstract}
The superior sensitivity, dynamic range, and mass measurement accuracy of suspended trapping pulse sequences for gas chromatography combined with Fourier transform mass spectrometry (GC/FTMS) separations of complex organic mixtures is demonstrated. By combining intense ionization conditions with a suspended trapping event prior to detection the working range of the trapped ion cell is increased by $10^{3}$. Improved detection limits are shown for the GC/FTMS separation of a peppermint oil, with the suspended trapping total ion chromatogram yielding 28 peaks, compared with 15 with a conventional trapping pulse sequence. A fivefold to fifteenfold improvement in signal-to-noise for suspended trapping measurements is also demonstrated with comparison spectra from separations of an unleaded gasoline sample. Suspended trapping spectra show little mass discrimination when an external ion reservoir is used, and chromatographic peak heights differ from conventional spectra by less than $30 \%$ if the initial ion population is within the space charge limit of the cell. Finally, average wide band mass measurement errors for components differing in concentration by several orders of magnitude are improved by a factor of 6 to 20 with suspended trapping compared with conventional trapping. For example, average errors of $8.7 \mathrm{ppm}$ are obtained for a suspended trapping GC/FTMS separation of peppermint oil from a single calibration table in which the analysis is performed in the absence of calibrant. ( $J$ Am Soc Mass Spectrom 1990, 1, 431-439)
\end{abstract}

$\mathrm{F}$ Tourier transform mass spectrometry (FTMS) has been promoted as an alternative to sector mass analyzers for high performance mass spectrometric detection of gas chromatographic (GC) effluent [1-12]. For example, simultaneous ion detection affords the fast scan rates necessary to maximize chromatographic performance for capillary GC. At reduced scan rates, GC/FTMS mass resolution exceeding 87,000 at mass 128 was achieved [6]. Low partper-million mass measurement accuracy over a broad mass range also has been demonstrated, which offers the prospects for routine on-line elemental analysis of mixture components $[7,8,11]$. Finally, fast scan rates and computer control of pulse sequence parameters permit various combinations of mass spectrometry experiments (e.g., alternate electron and chemical ionization) to be acquired during a single chromatographic separation as a means to maximize the chemical information that is generated $[5,6,8]$.

Despite these advantages, GC/FTMS is only infrequently applied to realistic problems in organic mixture analysis. One important limitation, the pressure mismatch between the GC and the analyzer trapped ion cell has been overcome. Whereas early interfaces

Address reprint requests to David A. Laude, Ir., Department of Chemistry, The University of Texas at Austin, Austin, IX 78712 . required that in excess of $99 \%$ of chromatographic effluent be diverted from the ion source to achieve acceptable analyzer performance [1-3], both pulsed introduction of the GC effluent [4-6] and later differential pumping between ion source and analyzer cell [13] remedied this problem. Detection limits for GC/FTMS are now similar to those obtained with other mass analyzers $[6,12]$. Unfortunately, a second deficiency of the GC/FTMS experiment that has not been adequately addressed is the small dynamic range of the trapped ion cell [14-17]. If sample pressures and ionization conditions can be carefully controlled to optimize the number of ions for detection, then this limitation is of little consequence. However, as with any measurement in which the neutral population fluctuates or is unknown, detection of chromatographic effluent with an invariant set of ionization parameters may generate ion populations that exceed the space charge limit. The problem is acute for GC/FTMS given the incompatibility between the cubic trapped ion cell with a typical dynamic range of $10^{2}$ and complex mixtures with detectable component concentrations that vary by $10^{6}$ or more [12]. Previous solutions to the dynamic range limitations of the cell usually involved some form of selective ionization, ion excitation, or resonance ejection [6, 18-23], but these techniques require prior knowledge of the ion 
population to be created and are of limited value in GC/FTMS applications. Instead, it is routine to employ compromise ionization conditions that sacrifice sensitivity to avoid space charge contamination of large components in the mixture; in effect, a narrow window of mixture component concentrations, between FTMS detection limits and trapped ion cell capacity, is selected for analysis.

We have investigated a variety of suspended trapping pulse sequences for FTMS that have been applied to fundamental studies of ion motion in multiple trapping reservoirs [24, 25], to extension of dynamic range of fluctuating ion populations [12], and to simplification of mass calibration [26]. In applications designed to improve dynamic range, intense ionization conditions are used to create large initial ion populations and thereby ensure maximum sensitivity. During a subsequent suspended trapping event, trap plate potentials are set to ground potentials to allow the free flight of ions along magnetic field lines in the vacuum chamber. The rate of ion flight from the cell is dependent upon changing coulombic repulsive effects, and thus is self-regulating. Within a readily determined time period after initiation of the suspended trapping event, an ion population below the cell space charge limit remains regardless of the initial number of ions in the cell, and reapplication of trapping potentials permits detection of high quality FTMS spectra. First evidence of the analytical potential of suspended trapping for GC/FTMS was the demonstration of space-charge-free spectra from injection onto a GC column of mixture components varying in concentration by $10^{6}$ [12]. No line broadening or peak shape distortion was observed and frequency shifts associated with the radial electric field established by the ion cloud were reduced to a few hertz. However, that work was limiled to simple two and three component mixtures. Among questions still to be addressed concerning suspended trapping as it applies to more complex mixtures are effects on chromatographic performance, FTMS limits of detection and dynamic range, quantitative analysis, and mass spectral quality. Presented here is a systematic evaluation of suspended and conventional trapping pulse sequences used in GC/FTMS separations of peppermint oil and unleaded gasoline samples.

\section{Experimental}

GC / FTMS instrumentation. The general instrument configuration for the GC/FTMS experiment employs a dual cell FTMS from Nicolet Analytical Instruments (Madison, WI) as the detector for a capillary gas chromatograph. The GC used is a Hewlett Packard (Palo Alto, CA) model 5890A with capillary split injection and flame ionization detector. A 1.9-cm diameter hole drilled in the GC housing and oven frame allows the transfer line to exit the GC. Samples are injected with a 20:1 split ratio onto a 12-m length $\times 0.330-\mu \mathrm{m}$ diameter capillary column with $0.5-\mu \mathrm{m} 5 \%$-phenylmethylsilicone stationary phase (SGE). The column exit is directly coupled inside the GC oven with a $1 / 32$ " zero dead volume union to the transfer line. At a helium carrier gas velocity of $21 \mathrm{~cm} / \mathrm{s}$, plate counts of $12,000-20,000$ for this column are typical, as determined for a test mixture with a flame ionization detection (FID). Carrier gas is introduced directly to the mass spectrometer source region and generates pressures of $1.2 \times 10^{-6}$ torr. Pressures in the analyzer cell are in the low $10^{-8}$ torr region.

The FTMS is described in detail elsewhere [12]. Briefly, the system includes a 3.0-T superconducting magnet with two adjacent $4.76-\mathrm{cm}^{3}$ stainless steel trapped ion cells separated by a $2-\mathrm{mm}$ conductance limit. Dual $700 \mathrm{~L} / \mathrm{s} 8^{\prime \prime}$ UHV diffusion pumps provide low $10^{-9}$ torr base pressures for both source and analyzer chambers. A flament mounted in the fringing field of the analyzer chamber generates an electron beam that traverses both cells and impinges on a collector mounted in the fringing freld of the source chamber.

FTMS acquisition and data parameters. Data acquisition from the FTMS was controlled with Nicolet software version 5.1R2. The suspended trapping pulse sequence employed was a modification of the conventional single resonance experiment that included a suspended trapping delay after the beam event. The pulse sequence was initiated with a $10-\mathrm{ms}$ quench pulse followed by electron ionization. For suspended trapping experiments, a $30-\mathrm{ms}, 40-\mu \mathrm{A}$ electron beam was employed for peppermint oil separations, and a $40-\mathrm{ms}, 60-\mu \mathrm{A}$ beam was used for unleaded gasoline separation. For all experiments, $-21 \mathrm{eV}$ electron beam was used to minimize formation of ions from helium carrier gas that would contribute to space charge distortion in the cell. During the beam event a $2.0 \mathrm{-V}$ potential was applied to the source and analyzer trap plates while the conductance limit was maintained at $0.0 \mathrm{~V}$ to equilibrate source and analyzer ion populations. During the subsequent suspended trapping event all electrodes were set to $0.0 \mathrm{~V}$ to allow the free flight of analyte ions that might contribute to space charge. Optimized suspended trapping times of 300 $\mu \mathrm{s}$ for the peppermint oil and $2 \mathrm{~ms}$ for the gasoline were used, based upon suspended trapping intensity profiles acquired prior to each GC/FTMS separation. Differences in optimum delay times are attributed to variation in cell cleanliness at the time experiments were performed. Excitation and detection events were performed in a $2.0-\mathrm{V}$ analyzer cell with $2.66-\mathrm{MHz}$ excitation bandwidth and a $3200-\mathrm{Hz} / \mu \mathrm{s}$ sweep rate followed by acquisition of $16-\mathrm{K}$ data points over an $800-\mathrm{KHz}$ bandwidth (low mass cutoff at $\mathrm{m} / \mathrm{z} 46$ ).

For comparison purposes, suspended trapping GC/FTMS separations were reproduced with identical ionization parameters but continuous trapping. However, these sets of ionization conditions are likely to 
result in severe space charge distortion in the spectra; to better represent continuous trapping GC/FTMS capabilities separations were also performed with a 10$\mathrm{ms}, 10-\mu \mathrm{A}$ beam to reduce space charge.

A single transient was stored every $0.3 \mathrm{~s}$ during each GC/FTMS separation. Total ion chromatograms (TIC) for each separation were generated by integrating the Fourier transform of the first 1-K data points in each spectrum. Data processing of selected transients included baseline correction, sine-bell apodization, and a magnitude-mode Fourier transform.

A commercial peppermint oil and an unleaded gasoline sample were analyzed as purchased. A neat 2.0 $-\mu 1$ sample of peppermint oil was injected with a $20: 1$ split ratio onto the GC column. For this separation the GC oven temperature was maintained at 70 ${ }^{\circ} \mathrm{C}$ for $3 \mathrm{~min}$ followed by a $10{ }^{\circ} \mathrm{C} / \mathrm{min}$ ramp for $15 \mathrm{~min}$ to a final temperature of $220^{\circ} \mathrm{C}$. For the gasoline separation, $2.0 \mu \mathrm{L}$ was injected with a $20: 1$ split ratio onto the column. The oven temperature was held at $30{ }^{\circ} \mathrm{C}$ for $1 \mathrm{~min}$, followed by a $10^{\circ} \mathrm{C} / \mathrm{min}$ ramp to a final temperature of $100{ }^{\circ} \mathrm{C}$.

\section{Results and Discussion}

To address the relative merits and potential deficiencies of suspended trapping pulse sequences for GC/FTMS measurements, the technique was contrasted directly with pulse sequences that employed continuous trapping. The only differences in conditions for the individual separations to be presented are the presence or absence of a suspended trapping event, and the intensity of the electron ionization event. Specific measures of chromatographic and mass spectral performance to be evaluated are chromatographic resolution, FTMS sensitivity and detection limits, GC/FTMS dynamic range, quantitative GC/FTMS analysis, FTMS accurate mass measurement, and mass discrimination in FTMS spectra. Each topic is addressed separately below.

GC / FTMS chromatographic resolution. Comparison separations performed with a FID indicated that band broadening associated with the GC/FTMS interface was negligible; for both detectors, peak widths for early eluting components were 2 to $3 \mathrm{~s}$. To maximize chromatographic performance it was therefore necessary to operate at or near maximum FTMS scan rates, between 3 and $4 \mathrm{~Hz}$ in these experiments. The suspended trapping pulse sequence would not be expected to significantly alter chromatographic time resolution because the sequence is at most a few milliseconds longer than the analogous conventional trapping pulse sequence. However, one concern about the suspended trapping experiment is that the use of intense ionization conditions might generate large numbers of ions throughout the vacuum chamber that because of inadequate quenching between scans might increase chemical noise in subsequent spectra with consequent
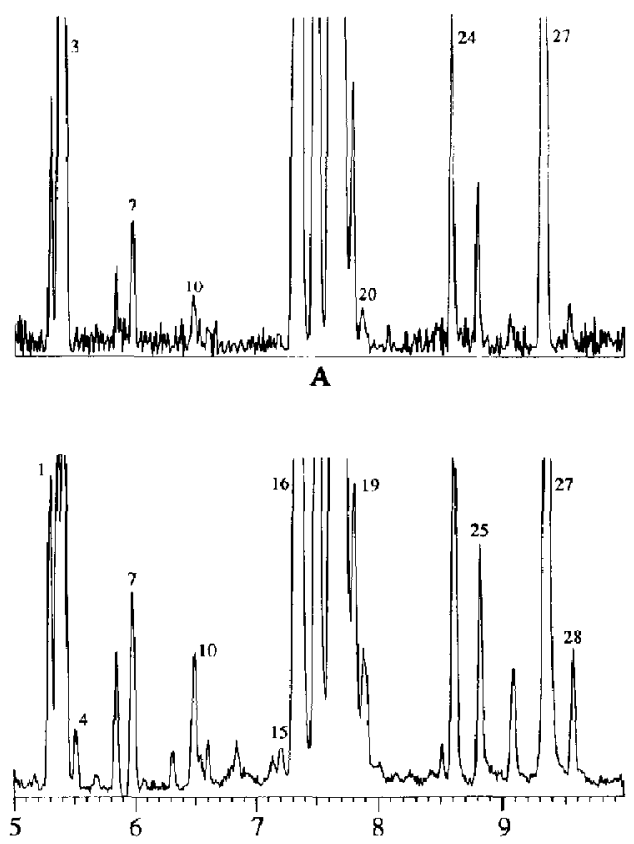

G C RUN TIME IN MINUTES

B

Figure 1. Total ion chromatograms for a 5-min segment in the GC/FTMS separation of a peppermint oil with (a) 10-ms, 10- $\mu \mathrm{A}$ electron beam and continuous trapping; and (b) $30-\mathrm{ms}, 40-\mu \mathrm{A}$ beam and a 300-us suspended trapping delay. Of the 28 detected components in (b), 15 were identified in (a).

chromatographic peak broadening. Presented in Figure 1 are TICs for the peppermint oil separations in which both low ionization conventional trapping and high ionization suspended trapping results are displayed. The narrow and well-shaped chromatographic peaks in the suspended trapping TIC in Figure $1 \mathrm{~b}$ are indistinguishable from the conventional trapping peaks in Figure 1a. This indicates that ordinary quench events are successful in purging the vacuum chamber of ions, and that the suspended trapping procedure is transparent to chromatographic performance.

Surprisingly, this observation did not hold true when intense ionization conditions were employed with a conventional trapping event. Figures 2 and 3 are segments of TICs from the unleaded gasoline separation in which three combinations of ionization conditions and trapping sequences are compared. Figures $2 b$ and $3 b$ for the unleaded gasoline separation are for a 30-ms, 60- $\mu \mathrm{A}$ electron beam event coupled with continuous trapping. Severe deterioration in chromatographic performance is observed, as best illustrated by comparing chromatographic peak profiles in Figure 2 at retention times of around $1.0 \mathrm{~min}$. A possible explanation for this distortion is that so many ions are created that the quench event between scans is incapable of eliminating all ions from the dual cell. 

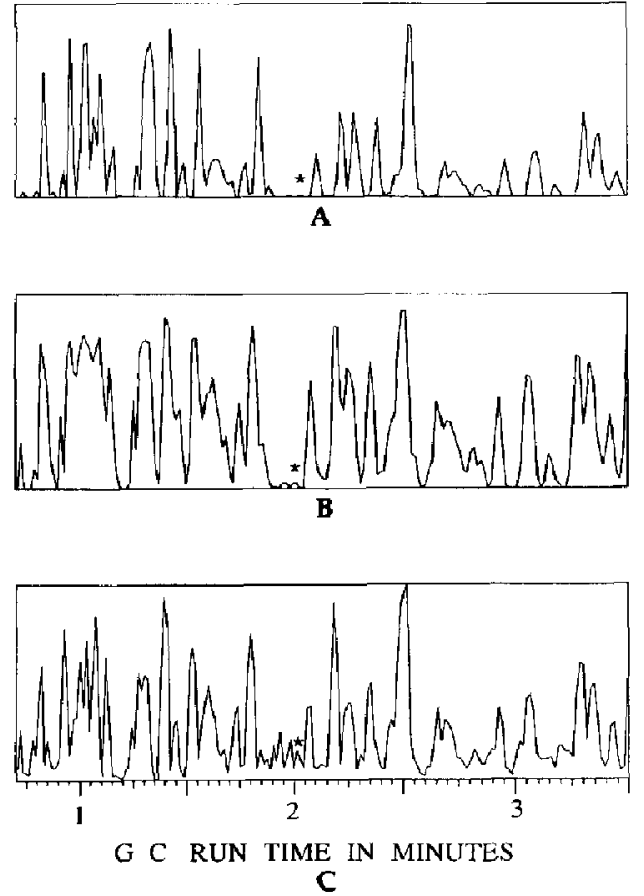

Figure 2. Total ion chromatograms from the GC/FTMS separation of an unleaded gasoline for the time period 0.5 to $3.5 \mathrm{~min}$ after injection (a) $10-\mathrm{ms}, 10-\mu \mathrm{A}$ electron beam and continuous trapping; (b) $40-\mathrm{ms}, 60-\mu \mathrm{A}$ electron beam and continuous trapping; and (c) 40-ms, 60- $\mu \mathrm{A}$ electron beam and a 2-ms suspended trapping delay. The peak denoted by * yields the spectra in Figure 4 .

However, if this were true then peak broadening would be observed for all large components. Instead, only for portion of the separation in which several components coelute dues the chromatography appear to deteriorate. A better explanation for the effect is that while intense ionization conditions enhance the signal for less abundant mixture components that would otherwise not be observed above the baseline, a proportional increase in signal intensity for more abundant components does not occur because of the limited range of the cell. In effect, a compression of signal intensities results which within a crowded region of the chromatogram appears as peak broadening. This effect is also observed, but to a much smaller extent, in the suspended trapping TIC in Figure 2c.

Sersitivity and detection limits in GC /FTMS. In these comparison separations, the sole factors responsible for the differences in detector sensitivity are the ionization conditions and the presence or absence of a suspended trapping event. For conventional trapping, sensitivity should increase in an approximately linear fashion as a function of the product of beam duration and electron current if below the space charge limit. This assumes that the time scale for the beam event is short compared to the chromatographic peak width so that changes in neutral populations during the beam event are small. Unfortunately, the limited dynamic range of the cell precludes indiscriminate application of intense ionization parameters with conventional trapping to achieve this proportional increase in sensitivity because space charge deterioration of important mixture components might occur. Nevertheless, low picogram detection limits have been demonstrated for electron ionization GC/FTMS by several groups $[6,8$, 12].

In evaluating sensitivity associated with suspended trapping GC/FTMS, the criticism could be made that some fraction of the initial ion population is always lost when the trap plate potentials are grounded, thereby adversely affecting the detection of trace components. It has been shown, however, that ion loss during suspended trapping is more than offset by adjusting the ionization conditions to produce far more ions than normally could be trapped in a standard experiment without exceeding the space charge. In fact, suspended trapping GC/FTMS detection limits can be better than those for conventional trapping under identical ionization conditions [12]. One possible explanation for this is the addition of analyte ions from the large external reservoir during suspended trapping.
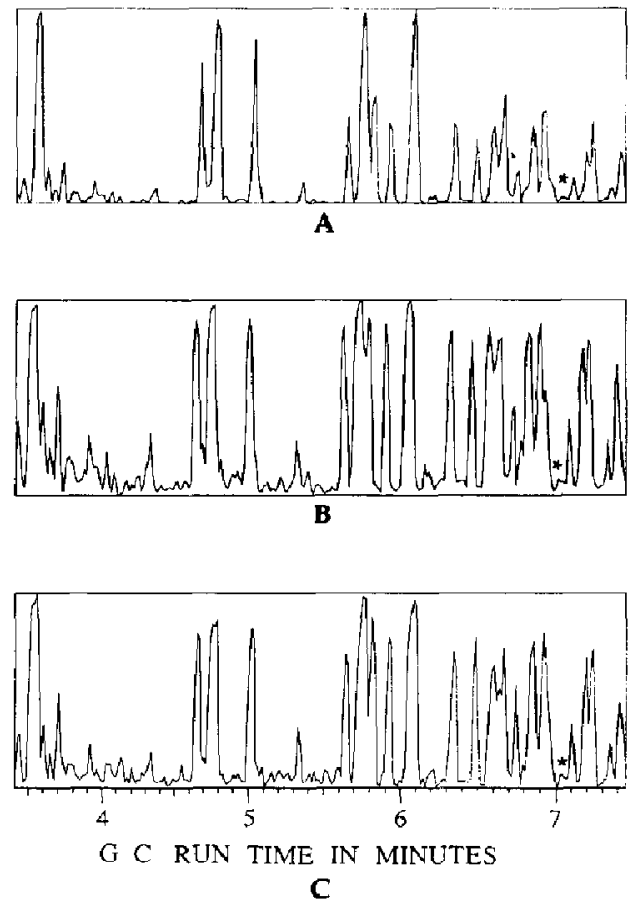

Figure 3. Total ion chromatograms from the GC/FTMS separation of an unleaded gasoline for the time period 3.5 to $7.5 \mathrm{~min}$ after injection (a) $10-\mathrm{ms}, 10-\mu \mathrm{A}$ electron beam and continuous trapping; (b) $40-\mathrm{ms}, 60-\mu \mathrm{A}$ electron beam and continuous trapping; and (c) 40-ms, 60- $\mu \mathrm{A}$ electron beam and a 2-ms suspended trapping delay. The peak denoted by * yields the spectra in Figure 5. 
Improvements in GC/FTMS detection limits as calculated from the relative intensities and durations of the ionization event should be factors of 12 and 24 for the peppermint oil and unleaded gasoline separations, respectively. Actual improvements will be smaller for the reasons listed above and are also difficult to determine because of differences in sampling over the elution profiles from separation to separation. Nevertheless, a real improvement in sensitivity for suspended trapping compared to conventional trapping is apparent from the peppermint oil reconstructions shown in Figure 1. The increased detection limits permit observation of at least 13 more components with suspended trapping than with conventional trapping. It could be argued that this is not a fair comparison because ionization conditions for the two separations are not the same. However, the ionization parameters used in acquiring the conventional trapping spectrum in Figure $1 \mathrm{a}, \mathrm{a} 10-\mathrm{ms}$ and $10-\mu \mathrm{A}$ beam, are actually at the high end of those typically used in previous GC/FTMS work because of space charge, while those used here for suspended trapping, $30 \mathrm{~ms}$ and $40 \mu \mathrm{A}$, would not have been considered for continuous trapping experiments.

The improvement in sensitivity is less apparent for the GC/FTMS separations of unleaded gasoline samples in Figures 2 and 3. However, this is a cosmetic effect attributed to the lack of a well-defined baseline that can serve as reference for changes in signal intensity in the complex mixture. In fact, sensitivity improvements are substantial and, for example, in the regions between 1.8 and $2.1 \mathrm{~min}$ in Figure 2 and 4.0 to $5.6 \mathrm{~min}$ in Figure 3, a large number of peaks are present in suspended trapping reconstructions that are not observed with low intensity ionization in Figures $2 \mathrm{a}$ and $3 \mathrm{a}$. Comparison spectra taken from selected low abundance peaks in these regions are presented in Figures 4 and 5 accompanied by signal-tonoise $(S / N)$ values for the base peaks in the captions. For six such low abundance components, the average improvement in $\mathrm{S} / \mathrm{N}$ for conventional and suspended trapping under intense ionization conditions was 5.0 and 5.2, respectively, when compared with spectra acquired with less intense ionization conditions.

Because both precolumn and postcolumn splits of sample effluent were used, it is difficult to quantify the limits of detection exhibited here for suspended trapping. Actual FTMS limits of detection are probably an order of magnitude below TIC detection limits because the algorithm used to calculate the reconstruction performs an integration over the entire spectral bandwidth. For example, the suspended trapping GC/FTMS spectrum in Figure 5 is for an almost indistinguishable peak in Figure 2c, yet spectral $S / N$ is 60 . Based upon an earlier systematic study of suspended trapping detection limits in GC/FTMS [12], it should be possible to extend detection limits below $1 \mathrm{pg}$ with simple changes in experiment design. These include on-column sample injection, the use of single fre-
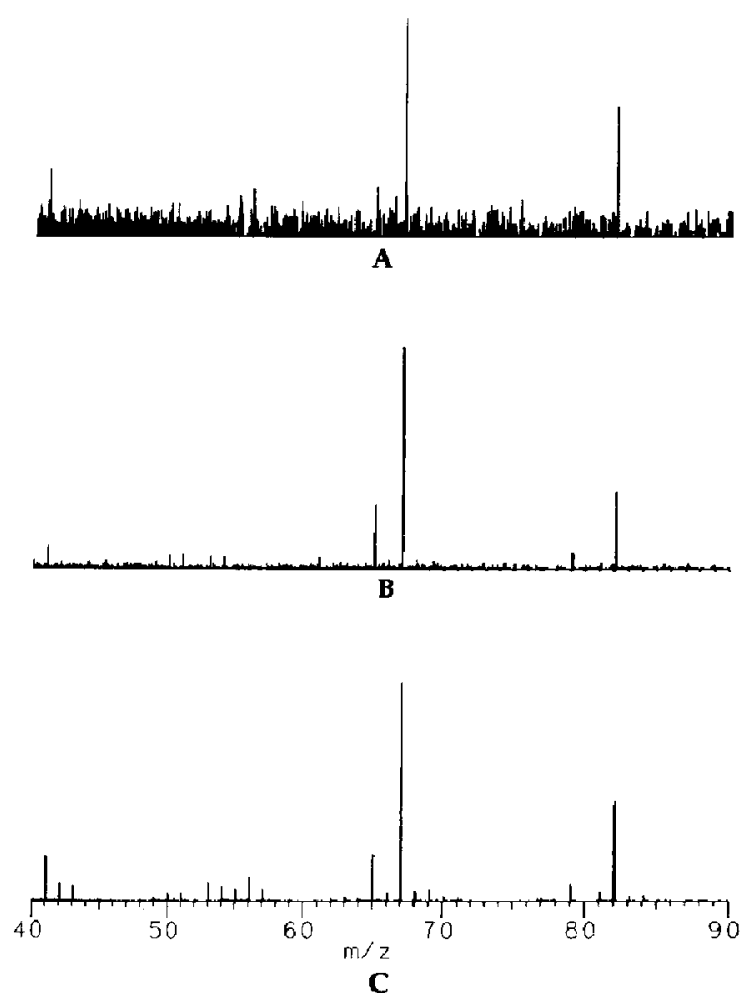

Figure 4. Comparison GC/FTMS spectra for the trace component eluting at $2.05 \mathrm{~min}$ in the unleaded gasoline spectrum. Conditions are as described corresponding to $(a-c)$ of Figure 2. Spectral $S / N$ values for the base peak in each spectrum are 9, 50 , and 142 , respectively.

quency excitation as an alternative to single ion monitoring, and $\mathrm{He}^{+}$ejection through excitation of the z-axis trapping motion.

Dynamic range. Suspended trapping was previously demonstrated to extend the working range of the FTMS trapped ion cell by four orders of magnitude beyond the $10^{2}$ range achieved with conventional trapping [12]. However, that demonstration was for sequential injections of a single component at increasing concentrations. The data generated for the peppermint oil and gasoline samples confurm for realistic mixtures the indicated advantages of suspended trapping for extending dynamic range. Spectral quality was retained for even the most abundant mixture components in every separation performed with suspended trapping. In contrast, conventional spectra generated under ionization conditions which led to space charge exhibited peak distortions, mass discrimination, and, as will be shown, large shifts in cyclotron frequency. Spectra acquired with reduced ionization conditions and conventional trapping were less susceptible to space charge effects, but because of inferior detection limits exhibited a similarly inadequate dynamic range. 

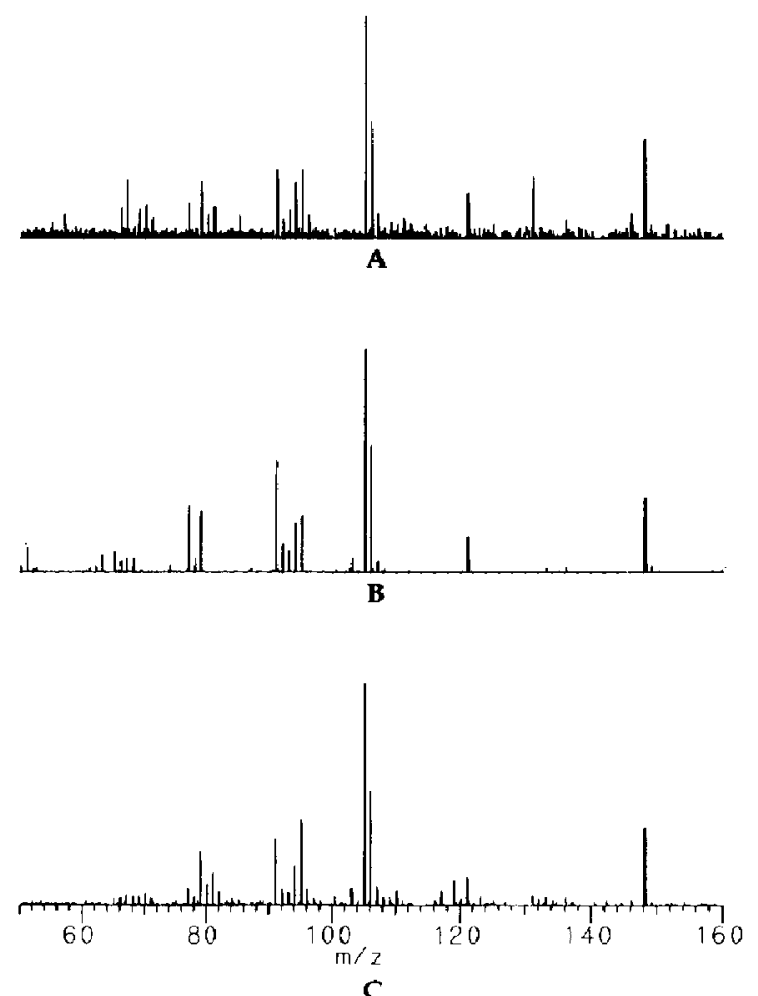

Figure 5. Comparison GC/FTMS spectra for the trace component eluting at $7.05 \mathrm{~min}$ in the unleaded gasoline spectrum. Conditions are as described corresponding to $(a-c)$ of Figure 3. Spectral $\mathrm{S} / \mathrm{N}$ values for the base peak in each spectrum are 26 , 139 , and 100 , respectively.

Mass measurement accuracy. One of the most stringent tests of space charge perturbation of the FTMS signal is a reduction in cyclotron frequency that is attributed to the radial electric field generated by the ion cloud [27-30]. Any effort to obtain accurate mass data must either account for this effect or reduce its contribution to the effective cyclotron frequency. Thus, the usual approaches taken to achieve low parts-permillion accurate mass measurement changes in ion population are to add an ion density-dependent term to the calibration equation and thereby correct for the shift $[29,30]$, or simply to operate the spectrometer under conditions that minimize the detected ion population. The first approach is difficult to implement when the sampling environment is not easily controlled. Recently, however, Gross [31] demonstrated some improvement to this approach by applying a correction factor based upon the abundances of calibrant ions present in the spectrum.

Minimizing the ion population in the cell through interactive control of experiment parameters is not readily accomplished given the dynamic changes in sample population in the GC/FTMS experiment. The advantage of suspended trapping is the ability to control the ion population without knowledge of the sample and without operator intervention. Simplified mass calibration of fluctuating sample populations is therefore simplified because the detected ion population is always below the space charge limit, yet at adequate levels to generate spectra of acceptable S/N. To demonstrate this, accurate mass measurement GC/FTMS measurements were performed in a procedure in which a calibration table was generated prior to a separation performed in the absence of calibrant. This approach has the advantage of minimizing chemical interference and reducing the background ion population in a cell of limited dynamic range [7].

For each of the three chromatographic separations of unleaded gasoline shown in Figures 2 and 3, a five-point calibration table was generated from perfluorotributylamine under conditions identical to those expected for the subsequent GC/FTMS separation. The $95 \%$ confidence limit was typically between 3 and $5 \mathrm{~Hz}$. Ultimately, the accurate mass measurement performance is limited by lack of spectral peak definition; for example, for a $1.0-\mathrm{MHz}$ bandwidth and $16-\mathrm{K}$ data points, significant mass errors are introduced even at relatively low masses, and best case average errors are between 10 to $15 \mathrm{~Hz}$ [7]. Table 1 presents the results for six representative components in the gasoline sample, selected to span a wide range of concentrations. Conventional trapping spectra acquired under intense ionization conditions exhibit errors of several hundred parts-per-miltion. The large positive errors in all spectra, but especially at low analyte concentrations, indicate that the calibration table was created from an ion population substantially below those detected during the separation. However, even if the calibration table was formed at a better approximation of the average ion population for mixture components, fluctuations in errors would still be more than $600 \mathrm{ppm}$. For these ionization and trapping conditions, then, a calibration equation that accounts for the ion cloud radial electric field is essential to accurate mass measurement. As also indicated in Table 1, the calibration table for conventional trapping GC/FTMS spectra acquired with a 10-ms, 10- $\mu \mathrm{A}$ beam better approximated the ion populations to be detected by GC/FTMS; low neutral populations introduced negative frequency shifts as high as $50 \mathrm{ppm}$, while at higher abundances components generated frequency shifts in error by hundreds of hertz in the other direction. The average error of $88 \mathrm{ppm}$ represents a fivefold improvement in mass accuracy, although this indicates the dominant error is still due to the uncorrected ion cloud electric field.

In contrast with conventional trapping spectra, mass measurement errors for suspended trapping separations in Table 1 were reduced to the expected data point limited error range of 10 to $15 \mathrm{ppm}$. Evidently the suspended trapping calibration table accommodated a broad range of initial ion populations despite the absence of an ion density radial electric field term in the calibration equation. The insertion of 
Table 1. Comparison accurate mass measurement data for the GC/FTMS separation of unleaded gasoline

\begin{tabular}{|c|c|c|c|c|c|c|c|c|c|}
\hline \multirow[b]{2}{*}{$\begin{array}{l}\text { Elution } \\
\text { time (min) }\end{array}$} & \multicolumn{3}{|c|}{$\begin{array}{c}\text { Suspended trapping } \\
60-\mathrm{mA}, 40-\mathrm{ms}^{-} \text {beam }\end{array}$} & \multicolumn{3}{|c|}{$\begin{array}{l}\text { Continuous trapping } \\
60-\mathrm{mA}, 40 \text {-ms } \mathrm{e}^{-} \text {beam }\end{array}$} & \multicolumn{3}{|c|}{$\begin{array}{c}\text { Continuous trapping } \\
10-\mathrm{mA}, 10-\mathrm{ms} \mathrm{e}^{-} \text {beam }\end{array}$} \\
\hline & $\begin{array}{c}\text { Relative } \\
\text { intensities }\end{array}$ & Mass & $\begin{array}{l}\text { Error } \\
\text { [ppm] }\end{array}$ & $\begin{array}{c}\text { Relative } \\
\text { intensities }\end{array}$ & Mass & $\begin{array}{l}\text { Error } \\
\text { (ppm) }\end{array}$ & $\begin{array}{c}\text { Relative } \\
\text { intensities }\end{array}$ & Mass & $\begin{array}{l}\text { Error } \\
\text { (ppm) }\end{array}$ \\
\hline 2.2 & 17.3 & $\begin{array}{l}55.05372 \\
83.08519 \\
98.11057\end{array}$ & $\begin{array}{r}-9.2 \\
-4.0 \\
15.9\end{array}$ & 33.3 & $\begin{array}{l}55.062750 \\
83.108727 \\
98.146861\end{array}$ & $\begin{array}{l}154.8 \\
279.2 \\
385.9\end{array}$ & 6.5 & $\begin{array}{l}55.052295 \\
83.080840 \\
98.103570\end{array}$ & $\begin{array}{l}-35.1 \\
-56.4 \\
-55.3\end{array}$ \\
\hline 7.0 & 30 & $\begin{array}{l}105.068811 \\
121.101509 \\
148.129070\end{array}$ & $\begin{array}{r}-10.1 \\
2.7 \\
29.8\end{array}$ & 41.1 & $\begin{array}{l}105.097254 \\
121.148664 \\
148.205510\end{array}$ & $\begin{array}{l}260.6 \\
392.1 \\
545.9\end{array}$ & 7.8 & $\begin{array}{l}105.067561 \\
121.166535 \\
148.117483\end{array}$ & $\begin{array}{r}-69.9 \\
44.2 \\
48.3\end{array}$ \\
\hline 1.74 & 67 & $\begin{array}{l}56.062543 \\
69.069703 \\
84.094238\end{array}$ & $\begin{array}{r}8.7 \\
-2.5 \\
10.6\end{array}$ & 185 & $\begin{array}{l}56.071798 \\
69.082639 \\
84.112869\end{array}$ & $\begin{array}{l}173.8 \\
184.8 \\
232.1\end{array}$ & 54 & $\begin{array}{l}56.062439 \\
69.069747 \\
84.093724\end{array}$ & $\begin{array}{r}6.9 \\
-1.9 \\
4.4\end{array}$ \\
\hline 7.7 & 89 & $\begin{array}{l}119.082859 \\
148.124740\end{array}$ & $\begin{array}{r}-22.4 \\
0.7\end{array}$ & 196 & $\begin{array}{l}119.116353 \\
148.186775\end{array}$ & $\begin{array}{l}258.8 \\
419.4\end{array}$ & 54 & $\begin{array}{l}119.081014 \\
148.118548\end{array}$ & $\begin{array}{l}-37.8 \\
-41.2\end{array}$ \\
\hline 1.4 & 159 & $\begin{array}{l}56.063681 \\
57.071345\end{array}$ & $\begin{array}{l}29.1 \\
25.7\end{array}$ & 194 & $\begin{array}{l}56.070994 \\
57.078512\end{array}$ & $\begin{array}{l}159.5 \\
151.3\end{array}$ & 303 & $\begin{array}{l}56.072945 \\
57.080223\end{array}$ & $\begin{array}{l}181.3 \\
194.3\end{array}$ \\
\hline 2.5 & 194 & $\begin{array}{l}57.070596 \\
99.122600\end{array}$ & $\begin{array}{l}12.6 \\
58.3\end{array}$ & 431 & $\begin{array}{l}57.082398 \\
99.198062\end{array}$ & $\begin{array}{l}218.4 \\
818.9\end{array}$ & 369 & $\begin{array}{l}57.076350 \\
99.159878\end{array}$ & $\begin{array}{l}113.4 \\
434.4\end{array}$ \\
\hline \multicolumn{2}{|c|}{ average error } & \multicolumn{2}{|c|}{$14.8 \pm 14.6 \mathrm{ppm}$} & \multicolumn{3}{|c|}{$309 \pm 176 \mathrm{ppm}$} & & \multicolumn{2}{|c|}{$88.3 \pm 108 \mathrm{ppm}$} \\
\hline
\end{tabular}

a 2-ms suspended trapping delay with $60-\mu \mathrm{A}, 40$-ms electron beam improved twentyfold the average errors of over $300 \mathrm{ppm}$ obtained with conventional trapping for the same ionization conditions. Some effort to improve on the suspended trapping accurate mass data was attempted with the peppermint oil separation, by doubling the number of data points defining each spectral peak. Results shown in Table 2 are from a suspending trapping GC/FTMS separation with $32-\mathrm{K}$ data points collected over a $1.0-\mathrm{MHz}$ bandwidth. The improved peak definition would be expected to improve the accuracy of mass assignment average, and in fact errors of $9.0 \mathrm{ppm}$ were obtained. Additional improvement would be expected through even better definition of mass spectral peaks, but conflicts with data storage and processing time become increasingly important when lengthy capillary GC separations are performed.

Quantitatize GC/FTMS. An apparent limitation of suspended trapping pulse sequences is the loss of quantitative information derived from integrated chromatographic peak heights. For example, in the suspended trapping reconstructions of the unleaded gasoline, relative peak heights for components in large abundance are leveled while peak heights for trace components are amplified above the baseline. However, this compression of relative abundances is not specific to suspended trapping; as discussed earlier, it occurs as well with conventional trapping under ionization conditions that generate ion populations above the space charge limit.

Below the space charge limit the quantitative behavior of suspended trapping spectra does not fare as badly as might be expected. This is because when the ion population is relatively small, ion efflux during suspended trapping will be governed to a greater extent by time-of-flight considerations rather than coulombic repulsion, and hence the ratio of ions would be less dependent on the size of the ion population. Evidence to support this comes from an evaluation of the peppermint oil reconstructions in Figure 1. As examples, relative heights for peaks $6,7,10,23,24$, and 26 in the suspended trapping TIC are in the ratio $0.50: 0.77: 0.41: 1.0: 0.25: 0.30$. The relative heights for these peaks in the conventional trapping TIC reconstruction are $0.58: 0.82: 0.55: 1.0: 0.49: 0.57$. The average difference is about $\mathbf{2 4 \%}$. Thus, although suspended trapping pulse sequences should not be employed when quantitative information is required, a reasonably qualitative estimate of the relative component abundances is still produced.

Mass discrimination in suspended trapping spectra. A second potentially significant liability of the suspended trapping pulse sequence is a skewing of relative ion abundances in a mass spectrum in favor of higher mass ions. This occurs because during the suspended trapping event, time-of-flight considerations alone would suggest the preferential flight of low mass ions from the cell. This low mass discrimination could have important consequences for any measurement that requires a quantitative representation between the ion population created and the one actually detected. Examples include the profiling of reactant and product ion abundances in ion-molecule reactions, and the use of mass spectral library data bases for spectrum identification.

A complete assessment of the mass dependent nature of ion flight from the cell is not considered here; instead, a direct comparison of relative abundances for spectra acquired by both conventional and 
Table 2. Accurate mass measurement data for the suspended trapping GC/FTMS separation of peppermint ail

\begin{tabular}{|c|c|c|c|}
\hline $\begin{array}{l}\text { Elution time } \\
\text { (min) }\end{array}$ & Mass (u) & $\begin{array}{l}\text { Molecular } \\
\text { formula }\end{array}$ & $\begin{array}{l}\text { Error } \\
\text { (ppm) }\end{array}$ \\
\hline 4.35 & $\begin{array}{r}115.055438 \\
82.077920 \\
67.053845\end{array}$ & $\begin{array}{l}\mathrm{C}_{9} \mathrm{H}_{8} \\
\mathrm{C}_{6} \mathrm{H}_{10} \\
\mathrm{C}_{5} \mathrm{H}_{7}\end{array}$ & $\begin{array}{r}10.5 \\
2.6 \\
-5.7\end{array}$ \\
\hline 5.22 & $\begin{array}{r}136.127439 \\
105.070800 \\
93.070302 \\
79.054068\end{array}$ & $\begin{array}{l}\mathrm{C}_{10} \mathrm{H}_{18} \\
\mathrm{C}_{9} \mathrm{H}_{9} \\
\mathrm{C}_{7} \mathrm{H}_{9} \\
\mathrm{C}_{6} \mathrm{H}_{7}\end{array}$ & $\begin{array}{r}21.1 \\
8.7 \\
4.6 \\
-2.0\end{array}$ \\
\hline 5.70 & $\begin{array}{l}101.097670 \\
\mathbf{8 3 . 0 5 6 6 0} \\
\mathbf{5 9 . 6 4 9 4 9 3}\end{array}$ & $\begin{array}{c}\mathrm{C}_{6} \mathrm{H}_{3} \mathrm{O} \\
\mathrm{C}_{6} \mathrm{H}_{11} \\
\mathrm{C}_{3} \mathrm{H}_{7} \mathrm{O}\end{array}$ & $\begin{array}{r}15.6 \\
1.6 \\
5.9\end{array}$ \\
\hline 6.70 & $\begin{array}{r}136.127922 \\
121.102085 \\
93.071140 \\
79.054613\end{array}$ & $\begin{array}{l}\mathrm{C}_{10} \mathrm{H}_{16} \\
\mathrm{C}_{9} \mathrm{H}_{13} \\
\mathrm{C}_{7} \mathrm{H}_{9} \\
\mathrm{C}_{6} \mathrm{H}_{7}\end{array}$ & $\begin{array}{r}24.0 \\
7.5 \\
13.6 \\
4.9\end{array}$ \\
\hline 7.30 & $\begin{array}{r}154.138413 \\
139.114091 \\
112.090382 \\
97.066233\end{array}$ & $\begin{array}{l}\mathrm{C}_{12} \mathrm{H}_{17} \\
\mathrm{C}_{9} \mathrm{H}_{15} \mathrm{O} \\
\mathrm{C}_{7} \mathrm{H}_{12} \mathrm{O} \\
\mathrm{C}_{6} \mathrm{H}_{9} \mathrm{O}\end{array}$ & $\begin{array}{l}20.7 \\
16.9 \\
18.8 \\
14.8\end{array}$ \\
\hline 7.40 & $\begin{array}{l}150.104985 \\
108.057394\end{array}$ & $\begin{array}{c}\mathrm{C}_{10} \mathrm{H}_{14} \mathrm{O} \\
\mathrm{C}_{7} \mathrm{H}_{8} \mathrm{O}\end{array}$ & $\begin{array}{l}7.1 \\
4.0\end{array}$ \\
\hline 7.6 & $\begin{array}{r}138.142183 \\
95.085489 \\
81.069085\end{array}$ & $\begin{array}{l}\mathrm{C}_{9} \mathrm{H}_{15} \\
\mathrm{C}_{7} \mathrm{H}_{11} \\
\mathrm{C}_{6} \mathrm{H}_{9}\end{array}$ & $\begin{array}{r}15.6 \\
-0.4 \\
-9.7\end{array}$ \\
\hline 8.2 & $\begin{array}{r}152.118657 \\
137.096210 \\
110.071953 \\
95.048650 \\
82.041067\end{array}$ & $\begin{array}{l}\mathrm{C}_{10} \mathrm{H}_{16} \mathrm{O} \\
\mathrm{C}_{9} \mathrm{H}_{13} \mathrm{O} \\
\mathrm{C}_{7} \mathrm{H}_{10} \mathrm{O} \\
\mathrm{C}_{6} \mathrm{H}_{7} \mathrm{O} \\
\mathrm{C}_{5} \mathrm{H}_{5} \mathrm{O}\end{array}$ & $\begin{array}{r}-5.9 \\
0.9 \\
-6.0 \\
-5.2 \\
-3.0\end{array}$ \\
\hline 8.5 & $\begin{array}{r}179.141903 \\
138.140253 \\
95.084927 \\
81.068877\end{array}$ & $\begin{array}{c}\mathrm{C}_{12} \mathrm{H}_{19} \mathrm{O} \\
\mathrm{C}_{10} \mathrm{H}_{18} \\
\mathrm{C}_{7} \mathrm{H}_{11} \\
\mathrm{C}_{6} \mathrm{H}_{9}\end{array}$ & $\begin{array}{r}-6.4 \\
-0.4 \\
-6.3 \\
-12.3\end{array}$ \\
\hline 9.2 & $\begin{array}{r}161.130807 \\
123.117526 \\
105.069438 \\
\mathbf{8 1 . 0 6 8 8 7 0} \\
79.053590\end{array}$ & $\begin{array}{l}\mathrm{C}_{12} \mathrm{H}_{17} \\
\mathrm{C}_{9} \mathrm{H}_{15} \\
\mathrm{C}_{8} \mathrm{H}_{9} \\
\mathrm{C}_{6} \mathrm{H}_{9} \\
\mathrm{C}_{6} \mathrm{H}_{7}\end{array}$ & $\begin{array}{r}-10.4 \\
5.7 \\
-4.2 \\
-12.4 \\
-8.1\end{array}$ \\
\hline & & \multicolumn{2}{|c|}{ average error $8.96 \pm 7.0$} \\
\hline
\end{tabular}

suspended trapping GC/FTMS is made. A correlation of mass-intensity pairs was made between the spectra in parts $b$ and $c$ of Figures 4 and 5, since they are of approximately equal $\mathrm{S} / \mathrm{N}$. The calculated correlation coefficients are greater than $97 \%$. Comparison probability-based-matching library searches of the 31985 NBS-NIH mass spectral library were also performed. The top-ranked search results for the suspended trapping spectra are $\mathrm{C}_{6}$-dienes for Figure $4 \mathrm{c}$ and methylpropylbenzenes for Figure $5 \mathrm{c}$. These are reasonable selections based upon expected component composition and approximate elution times.

Several explanations are possible for the minimal distortions of relative mass abundances in suspended trapping spectra. Clearly a model for ion flight from the cell based strictly upon time-of-flight considerations is inadequate and offsetting factors must be considered. For example, time-of-flight arguments break down when large coulombic repulsive forces are present early in the suspended trapping event, and mass dependence of ion flight is not easily described. A second factor is the influx of ions from the 38-cm external reservoir during suspended trapping [24]. Finally, the observation that ions are often retained in the cell for several milliseconds indicates that some low energy ions never escape; this may be due to small residual potential applied to the trap plates. Such ions would be preferentially retained on the basis of kinetic energy and would not exhibit mass discrimination.

\section{Conclusion}

Suspended trapping is demonstrated to enhance several aspects of GC/FTMS performance in comparison to conventional techniques. The combination of in- 
tense ionization conditions with suspended trapping can increase the limits of detection by an order of magnitude or more and simultaneously extends the working range of the trapped ion cell by four orders of magnitude. All adverse efferts of space rharge are eliminated with suspended trapping, and, in particular, low parts-per-million mass measurement accuracy can be achieved from a single calibration equation for widely varying sample concentrations encountered in GC separations. Suspended trapping is not recommended for applications in which quantitative information about relative component abundances is sought, although a qualitative measure of signal intensity is still possible for initial ion populations that are generated below the space charge limit. Finally, the expected skewing of relative mass intensities toward high mass is not observed, and the successful search of mass spectral libraries with suspended trapping spectra is possible.

\section{Acknowledgment}

This work is supported by the Welch Foundation and by a grant from the Texas Advanced Technology and Research Program.

\section{References}

1. Wilkins, C. L.; Giss, G. N.; White, R. L.; Brissey, G. M.; Onyiriuka, E. C. Anal. Chem. 1982, 54, 2260-2264.

2. Ledford, E. B., Ir.; White, R. L.; Ghaderi, S.; Wilkins, C. L.; Gross, M. L. Anal. Chem. 1980, 52, 2450-2451.

3. White, R. L.; Wilkins, C. L. Attal. Chem. 1982, 54, $2443-2447$.

4. Sack, T. M.; Gross, M. L. Anal. Chem. 1983, 55, 2419-2421.

5. Laude, D. A., Jr.; Johlman, C. L.; Brown, R. S.; Wilkins, C. L. Fres. Z. Anal. Chem. 1986, 324, 839-845.

6. Sack, T. M.; McCrery, D. A.; Gross, M. L. Anal. Chem. $1985,57,1290-1295$.

7. Johlman, C. L.; Laude, D. A., Jr.; Wilkins, C. L. Anai. Chem. 1985, 57, 1040-1044.

8. Johlman, C. L.; Laude, D. A., Jr.; Brown, R. S.; Wilkins, C. L. Anal. Chem. 1985, 57, 2726-2728.
9. Wilkins, C. L. Science 1983, 222, 291-296.

10. Laude, D. A., Jr.; Brissey, G. M.; Ijames, C. F.; Brown, R. S.; Wilkins, C. L. Anal. Chem. 1984, 56, 1163-1168.

11. Laude, D. A., Jr.; Johlman, C. L.; Cooper, J. R.; Wilkins, C. L. Antal. Chem. 1985, 57, 1044-1049.

12. Hogan, J. D.; Laude, D. A., Jr. Anal. Chem. 1990, 62, $530-535$.

13. Nicolet Analytical Instruments. Nicolet Analytical Instruments Guide, Madison, WI, 1985.

14. Castro, M. E.; Russell, D. H. Antal. Chem. 1985, 57, 2290-2293.

15. Wang, T. L.; Ricca, T. L.; Marshall, A. G. Anal. Chem. 1986, 58, 2935-2938.

16. Allemann, M.; Kofel, P.; Kellerhals, HP; Wanczek, K.-P. Int. 1. Mass Spec. Ion Proc. 1987, 75, 47-54.

17. Hunter, R. L.; Sherman, M. G.; McIver, R. T., Ir. Int. I. Mass Spec. Ion Phys. 1983, 50, 259-274.

18. Allemann, M.; Kofel, P.; Kellerhals, HP; Wanczek, K.-P. Int. J. Mass Spec. Ion Proc. 1987, 75, 47-54.

19. van der Hart, W. J.; van de Guchte, W. J. Int. J. Mass Spec. Ion Proc. 1988, 82, 17-31.

20. Noest, A. J.: Kort, C. W. F. Comp. and Chem, 1983, 7, 81-86.

21. deKoning, L. J.; Fokkens, R. H.; Piuske, F. A.; Nibbering, N. M. M. Int. J. Mass Spec. Ion Proc. 1987, 77, 95-105.

22. Chen, L.; Marshall, A. G. Int. J. Mass Spec. Ion Proc. 1987, 79, 115-125.

23. Marshall, A. G.; Wang, T.-C. L.; Ricca, R. L. I. Am. Chem. Soc. 1985, 707, 7893-7897.

24. Hofstadler, S. A.; Laude, D. A., Jr. Int. I. Mass Spec. Ion Proc., 1990, 97, 151-164.

25. Hofstadler, S. A.; Laude, D. A., Jr. Int. J. Mass Spec. Ion Proc., in press.

26. Beu, S. C.; Laude, D. A., Jr. Anal. Chem. 1989, 61, 2422-2427.

27. Ledford, E. B., Jr.; Ghaderi, S.; White, R. L.; Spencer, R. B.; Kulkarni, P. S.; Wilkins, C. L.; Gross, M. L. Anal. Chem. 1980, 52, 463-468.

28. Jeffries, J. B.; Barlow, S. E.; Dunn, G. H. Int. J. Mass Spec. Ion Proc. 1983, 54, 169-187.

29. Francl, I. J.; Sherman, M. G.; Hunter, R. L.; Locke, M. J.; Bowers, W. D.; McIver, R. T., Jr. Int. T. Mass Spec. Ion Proc. 1984, 54, 189199.

30. Ledford, E. B., Jr.; Rempel, D. L.; Gross, M. L. Anal. Chem. 1984, 56, 2744-2748.

31. Gross, M. L., private communication. 